See discussions, stats, and author profiles for this publication at: https://www.researchgate.net/publication/341642700

\title{
Urban climate services: climate impact projections and their uncertainties at city scale
}

Article · May 2020

DOI: 10.35614/ISSN-2341-6408-IK-2020-05-RL

CITATIONS

0

9 authors, including:

Bénédicte Bucher

Institut national de l'information géographique et forestière

78 PUBLICATIONS 752 CITATIONS

SEE PROFILE

Sidonie Christophe

Institut national de l'information géographique et forestière

93 PUBLICATIONS 536 CITATIONS

SEE PROFILE

Some of the authors of this publication are also working on these related projects:
READS

139

A Zenaida Chitu

National Institute of Hydrology and Water Management

28 PUBLICATIONS 155 CITATIONS

SEE PROFILE

Project Towards better tailored weather and marine forecasts in the Arctic to serve sustainable economic activities and infrastructure (TWASE) View project

Project $\quad$ TopDad project View project 


\title{
Urban climate services: climate impact projections and their uncertainties at city scale
}

\author{
In many cities across Europe, both urban authorities and private actors have made \\ strong commitments to adapt to future climate changes. Although a lot of climate \\ information is available at the global and regional scale, this is often not the case at \\ the local urban scale. Moreover, such information should account for a wide range of \\ uncertainty factors ranging from global to city-scale development scenarios to \\ uncertainties due to model errors. In an effort to lay the methodological groundworks \\ for reliable urban climate services, URCLIM explores a compound handling of these \\ uncertainties for various European cities and applies it to the assessment of \\ adaptation measures.
}

\author{
BERT VAN SCHAEYBROECK ${ }^{1}$, BÉNÉDICTE BUCHER ${ }^{3}$, ZENAIDA CHITU², SIDONIE CHRISTOPHE ${ }^{3}$, CARL FORTELIUS $^{4}$, \\ RAFIQ HAMDI', VALÉRY MASSON ${ }^{5}$, ADRIAAN PERRELS ${ }^{4}$, BEN WICHERS SCHREUR ${ }^{6}$ \\ 'Royal Meteorological Institute of Belgium (RMI), Belgium \\ 2 Meteo Romania, Romania \\ ${ }^{3}$ Univ Gustave Eiffel, LASTIG, IGN, ENSG, France \\ ${ }^{4}$ Finnish Meteorological Institute, Finland \\ ${ }^{5}$ Météo France, France \\ ${ }^{6}$ Koninklijk Nederlands Meteorologisch Instituut, Netherlands
}

The URCLIM project and the uncertainty issue - Climate change will be strongly felt in cities through increased health and socio-economic risks. This originates from the strong urban exposure due to high density in population, infrastructure and emissions, but also from increased risks due to more extreme weather conditions. Moreover, the urban heat island effect (UHI; Oke et al., 2017) leads to temperatures that are typically higher within the city than in the surrounding rural areas. Especially during heat waves, the absence of night-time cooling poses a threat to the most vulnerable in the population. Following the Paris Agreement, cities worldwide committed to introduce sustainable climate-resilient solutions, for instance through the Covenant of Mayors. In order for these cities to develop well-informed plans for climate action, reliable information is required (Bader et al., 2018). Such information necessitates an accurate evaluation of uncertainties owing to the uncertain pace of global warming, uncertainty in urban development, and shortfalls in the impact evaluation tools for local scales. By combining the expertise in urban climate, geomatics, urban mapping, socio-economics and health impacts, URCLIM aims to realize a proof of concept for integrated Urban Climate Services (UCS) for the metropolitan areas of Helsinki, Toulouse, Brussels, Amsterdam, and Bucharest obtained through a close collaboration with city authorities.
URCLIM objectives \& purposes The objective of developing UCS at the scale pertinent for urban planners is currently being established through 1) the production of high-resolution urban maps for incorporation in urban climate models, obtained using a generic processing chain that is easily generalizable to other cities, (https://github.com/orbisgis/geoclimate), 2) development of methodological best practices for urban impacts (see next paragraph), 3) assess the separate and combined impact of adaptation strategies and climate-change and city-development scenarios, and, 4) co-creation of innovative $3 D$ visualization and data interaction tools.

Methods \& uncertainty exploration URCLIM aims to distil UCS information from raw data taken from state-of-the-art 
climate projections and observational datasets. To estimate uncertainties, it is necessary to take a close look at the data-generation process. Indeed, depending on the impact different steps are required, each of which is associated with uncertainty factors. URLIM has considered these uncertainties in detail for UHI, floods, air quality, human comfort and socio-economic impacts as for instance shown in Fig. 1. One can distinguish the uncertainties that the scientists aim to minimize (observational, model or analysis uncertainties) from those associated with the unknown future including scenarios for greenhouse gases as well as city-context scenarios or intervention scenarios. Each step can also be categorized by one of the components of risk: hazards (orange colour in Fig. 1), exposure or vulnerability (green). A major URCLIM achievement is the development of a methodology for uncertainty propagation from the global to the urban scale. More specifically, a computationally-cheap method for producing decades-long physically-coherent climate simulations, obtained by downscaling the CORDEX ensemble of regional climate model projections down to kilometre resolution.

Prospects \& Follow-up - URCLIM provides a proof-of-concept for science-based Urban Climate Services for a few cities with a strong focus on generalizability and aimed at the most prominent urban impacts. Generaliz-

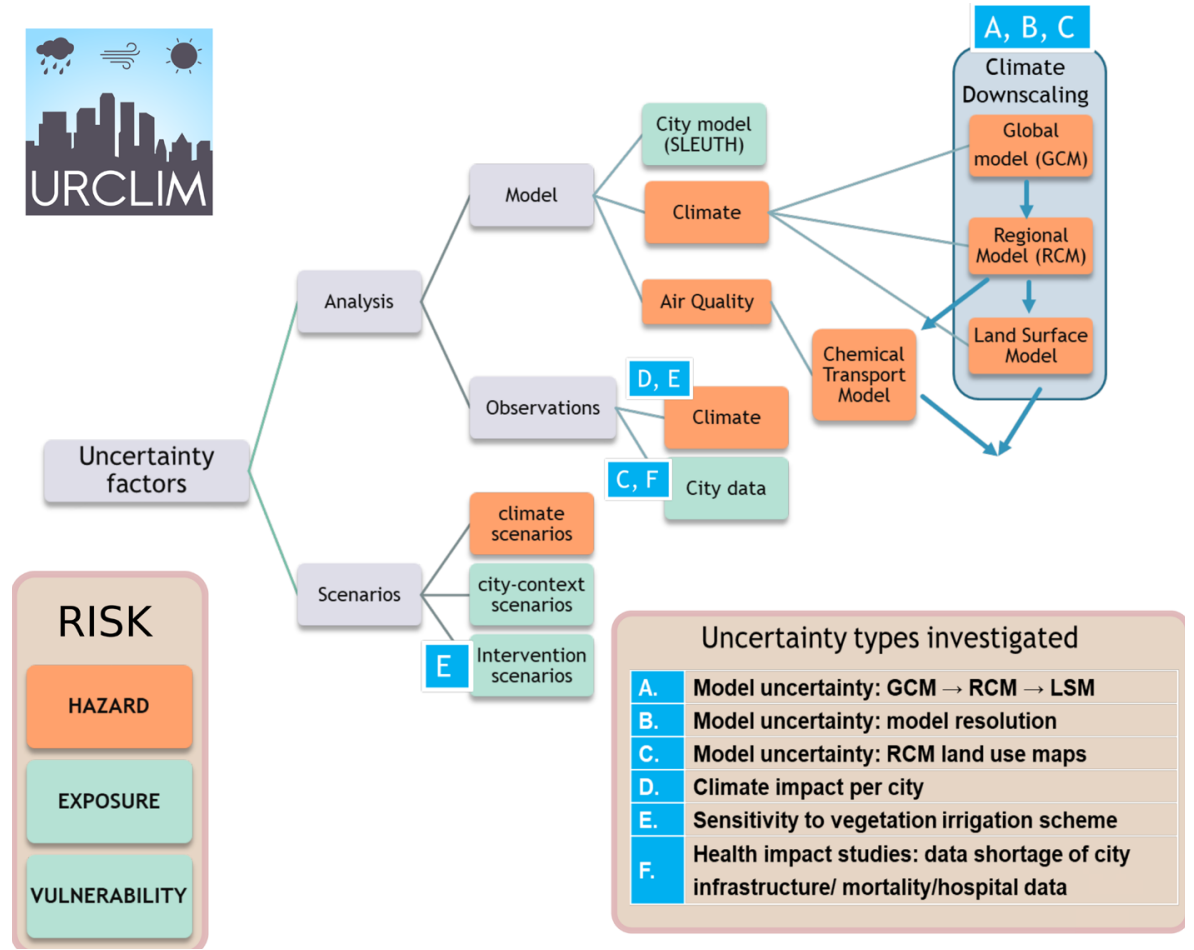

FIG 1: Steps necessary to arrive at the raw data necessary to distil UCS information. A few uncertainty factors affecting this process and investigated in URCLIM, specified in the table are indicated in the scheme.

ability is ensured by means of opensource and open-access tools to generate high-resolution urban maps, the use of freely available CORDEX data and smart visualization tools, in close collaboration with city actors.

Acknowledgements: This work received funding from EU's H2O2O Research and Innovation Program under Grant Agreement number 690462. 